\title{
Real world or wake-up call: Surgical aortic valve replacement versus transcutaneous aortic valve replacement
}

\author{
Tomas A. Salerno, MD, ${ }^{\mathrm{a}}$ and Alexandre C. Ferreira, $\mathrm{MD}^{\mathrm{b}}$
}

\footnotetext{
From the ${ }^{\mathrm{a}}$ Division of Cardiothoracic Surgery, University of Miami School of Medicine, Miami, Fla; and ${ }^{\mathrm{b}}$ Cardiology Department, Jackson Memorial Hospital, Miami, Fla. Disclosures: Authors have nothing to disclose with regard to commercial support.

Received for publication Aug 27, 2015; accepted for publication Aug 27, 2015; available ahead of print Oct 6, 2015.

Address for reprints: Tomas A. Salerno, MD, Division of Cardiothoracic Surgery (R-114), University of Miami School of Medicine, PO Box 016960, JMH-East Tower Room 3072, Miami, FL 33136 (E-mail: tsalerno@ med. miami.edu).

J Thorac Cardiovasc Surg 2015;150:1580-1

$0022-5223 / \$ 36.00$

Copyright $($ C 2015 by The American Association for Thoracic Surgery

http://dx.doi.org/10.1016/j.jtcvs.2015.08.099
}

Until recently, surgical aortic valve replacement (SAVR) was the only available strategy for long-term treatment of symptomatic degenerative aortic stenosis (AS). Despite the ominous prognosis of medically treated patients with severe AS who had indications for surgery, many were just too old and/or frail to undergo SAVR and were never offered surgery. Transcutaneous aortic valve replacement (TAVR) was developed to fulfill this unmet need and to provide a glimpse of hope to a growing aging population with extreme risk or those deemed inoperable.

A review ${ }^{1}$ of the Society of Thoracic Surgeons (STS) database indicates that only $6 \%$ of patients undergoing SAVR are high risk by virtue of a STS score $>8$. There has been a growing appeal to evaluate TAVR as an alternative to SAVR in an intermediate-risk population of patients with STS score $>4$. This intermediate-risk population represents about another $14 \%$ of the total surgical population, leaving still $80 \%$ of the total surgical patient population considered low risk (STS score, <4). This is the last frontier to be conquered by TAVR before SAVR becomes nearly obsolete as the first avenue for the treatment of patients with AS.

Two randomized, prospective, high-risk cohort, controlled clinical trials ${ }^{2,3}$ performed in highly selected US surgical centers (ie, the Placement of Aortic Transcatheter Valves [PARTNER] trial IA and the CoreValve US Pivotal trial), demonstrated that noninferiority, and even TAVR superiority, could be achieved in high-risk, operable patients, thereby opening the floodgates for expanded TAVR clinical trials.

More contemporary reports of a high-risk population of patients in the PARTNER II S3 trial, using the secondgeneration Sapien 3 valve (Edwards Lifesciences, Irvine, Calif) (average STS score, 8.6), and the Evolut R CEmark registry (average STS score, 7) have achieved 30 -day mortality rates under $3 \%$ and stroke rates under $2 \%$, event rates that are hard to fathom with any surgical approach, even in an intermediate-risk population. ${ }^{4,5}$

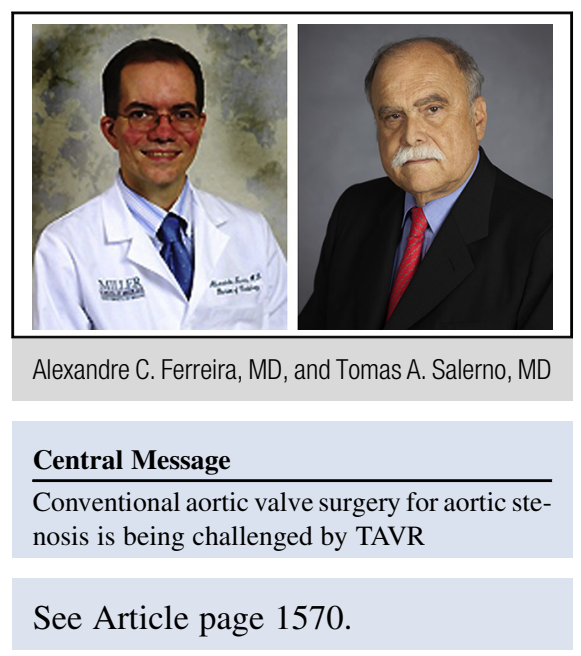

The retrospective report by Muneretto and colleagues ${ }^{6}$ in this issue of the Journal compares TAVR versus SAVR versus sutureless aortic valve prostheses, the latter being the latest technology that allows SAVR implantation without valve suturing, thereby shortening cardiopulmonary bypass and crossclamping times. In this propensitymatched, multicenter comparative analysis, a 30-day mortality of $3.4 \%, 5.8 \%$, and $9.8 \%$ for SAVR, sutureless valve, and TAVR, respectively, was achieved; pacemaker insertion of $3.9 \%, 9.8 \%$, and $14.7 \%$; and survival at 24 months of $91.3 \%, 95 \%$, and $80 \%$ all favored surgery over TAVR. Furthermore, the composite major adverse cardiac and cerebrovascular event and perivalvular leak rates of $93 \%, 96 \%$, and $77 \%$, respectively, suggests a competitive advantage of surgery over TAVR in a real-world population.

The limited influence this article will have on the realworld practice of SAVR lies on the inherent limitation of its design, its retrospective nature, and the presence of confounders that can never be totally addressed by propensity matching. Rigorous randomized clinical trials are required. This report is at odds with the recently presented results of the intermediate-risk PARTNER II S3 trial, ${ }^{7}$ which enrolled 1076 patients with average STS score of 5.3\% and demonstrated a 30-day mortality of $1.1 \%$, stroke rate of $2.6 \%$, pacemaker implantation of $10.1 \%$, and moderate-to-severe perivalvular leak of $3.8 \%$. Therefore, until Surgical Replacement and Transcatheter Aortic Valve Implantation trial results become available, superiority of SAVR over TAVR in intermediate-risk populations, except for pacemaker 
implantation and reduced perivalvular leak, will not be known.

In the real world, surgeons who have been involved in TAVR implantation are beginning to favor TAVR for the population of patients with AS who are elderly, have serious comorbidities, or who require redo operations. Interventional cardiologists continue to push the envelope to expand the use of TVAR to a lower-risk population of patients. The Nordic Aortic Valve Intervention Trial (NOTION) clinical trial $^{8}$ already reported comparable outcomes (mortality/ stroke) at 2 years in the youngest and lowest-risk population to date (average STS scores, 2.9-3.1). Even in this low-risk population, demonstrable benefits of TAVR are shown by lower bleeding risk, reduced atrial fibrillation, and less acute kidney injury compared with SAVR.

Issues that remain to be addressed with TAVR are durability and hemodynamic performance, perivalvular leaks, and the rather high need for pacemaker implantation. The PARTNER IA trial is demonstrating durable and favorable hemodynamic performance at 5 years. ${ }^{9}$ The Sapien 3 device, approved by the Food and Drug Administration in 2015 , has an outside skirt in the valve that minimizes or prevents perivalvular leaks, and initial clinical results are promising. What is left is the rather high need for pacemaker implantation, mostly when using the CoreValve device (Medtronic, Minneapolis, Minn), but also with the sutureless aortic prosthesis reported by Muneretto and colleagues. ${ }^{6}$ The question is whether TAVR should be offered as the first avenue of treatment to all patients with AS, regardless of risk. The history surrounding coronary artery bypass grafting versus percutaneous coronary intervention appears to be repeating and, in many ways, may be applicable to what is happening with SAVR and TAVR. May this be a wake-up call for surgeons who need to realize they must be involved in activities other than the operating room, becoming more active participants in new technologic advancements in the treatment of heart disease.

We hope societies will continue to emphasize the need for an integrated approach for the treatment of patients with AS via a team approach (eg, surgeons and cardiologists), and train the next generation of resident physicians and surgeons into what will become a new specialty area of cardiac surgery.

\section{References}

1. Thourani VH, Suri RM, Gunter RL, Sheng S, O'Brien SM, Ailawadi G, et al Contemporary real-world outcomes of surgical aortic valve replacement in 141,905 low-risk, intermediate-risk, and high-risk patients. Ann Thorac Surg. 2015;99:55-61.

2. Kodali SK, Williams MR, Smith CR, Svensson LG, Webb JG, Makkar RR, et al Two-year outcomes after transcatheter or surgical aortic valve replacement. $N$ Eng J Med. 2012;366:1686-95.

3. Reardon MJ, Adams DH, Kleiman NS, Yakubov SJ, Coselli JS, Deeb GM, et al 2-Year outcomes in patients undergoing surgical or self-expanding transcatheter aortic valve replacement. J Am Coll Cardiol. 2015;66:113-21.

4. The PARTNER II trial: Placement of AoRTic TraNscathetER Valves. Available at https://www.clinicaltrials.gov/ct2/show/NCT01314313?term=THE+PARTNER+ II+TRIAL\&rank=1. Accessed February 27, 2015.

5. The Medtronic CoreValveTM Evolut RTM CE Mark Clinical Study 2015. Available at: https://www.clinicaltrials.gov/ct2/show/NCT01876420?term=NCT0187 6420\&rank=1. Accessed February 27, 2015.

6. Muneretto C, Alfieri O, Cesana BM, Bisleri G, De Bonis M, Di Bartolomeo R, et al. A comparison of conventional surgery, TAVR and sutureless valves in "real world" patients with aortic stenosis and intermediate-high risk profile. $J$ Thorac Cardiovasc Surg. 2015;150:1570-9.

7. Kodali S. Thirty-day outcomes with Sapien 3 lowest seen with balloon-expandable TAVR. Abstract presented at: American College of Cardiology Annual Scientific Session; March 15, 2015; San Diego, CA.

8. Thyregod HG, Steinbrüchel DA, Ihlemann N, Nissen H, Kjeldsen BJ, Petursson P et al. Transcatheter versus surgical aortic valve replacement in patients with severe aortic valve stenosis: 1-year results from the all-comers NOTION randomized clinical trial. J Am Coll Cardiol. 2015;65:2184-94.

9. Mack MJ, Leon MB, Smith CR, Miller DC, Moses JW, Tuzcu EM, et al. 5-Year outcomes of transcatheter aortic valve replacement or surgical aortic valve replacement for high surgical risk patients with aortic stenosis (PARTNER 1): a randomised controlled trial. Lancet. 2015;385:2477-84. 